\title{
Lexicalized Meaning and the Internal Temporal Structure of Events ${ }^{1}$
}

\author{
Malka Rappaport Hovav \\ The Hebrew University of Jerusalem \\ mhovav@mscc.huji.ac.il
}

December 2006

\section{Background}

Most current studies of aspect assume the existence of the four Vendler classes: states, activities, achievements and accomplishments. Despite the fact that other classifications have been offered, (for example, those in Mourelatos 1978, Bach 1981, and Carlson 1981) none has achieved the status of the Vendler classification. Often, linguists take these classes to be a linguistic fact, and then attempt to come up with theories which explain their existence and their properties, usually by offering basic elements of meaning and modes of composition that together produce just these four aspectual classes.

One question which arises in the context of this enterprise is what aspectual classes are classes of. While the title of Vendler's (1957) paper ("Verbs and Times") leads one to assume that that Vendler was classifying verbs, he seemed to have been aware that he was really classifying larger linguistic units. The properties which define the Vendler classes are dynamicity, duration and telicity, at least some of which are not determined once and for all at the lexical level, but, rather, at the VP level, as a result of aspectual composition (Dowty 1979, Krifka 1992, 1998, Verkuyl 1989, among others). Thus, one dominant class of approaches assumes that the Vendler classes are classes of eventdenoting predicates corresponding to the $\mathrm{VP}^{2}$ But this returns us to the question of the relationship between the meaning of a verb and the aspectual class of the VP it appears in. Another way of phrasing this question would be: do verbs themselves have inherent aspectual properties which determine the classification of the VPs they appear in? There must be some such lexical difference to explain why the nature of the direct object of verbs like eat and draw affects the classification of the VP (eat apples vs. eat five apples; draw a picture vs. draw pictures), while the direct object of verbs like push and tickle does not (push a cart vs. push carts; tickle the child vs. tickle children).

Vendler (1957) describes the classes in terms of time schemata, and the criteria for his classification mostly have to do with internal temporal properties which interact with time-related diagnostics. The diagnostics for the Vendler classes include appearance and interpretation in the progressive, entailments from the progressive to the perfect,

\footnotetext{
${ }^{1}$ I would like to thank John Beavers, Edit Doron, Hana Filip, and Anita Mittwoch for extremely helpful discussion and correspondence on the issues treated in this paper. Thanks also to Hana Filip, Beth Levin and Susan Rothstein for comments on an earlier draft which led to significant improvements. This research was supported by The Israel Science Foundation (grant \# 806/03).

${ }^{2}$ In what follows, for ease of exposition, I will use the term "event-denoting," instead of "eventualitydenoting,", though I will be using the term "event" to refer to all aspectual types, despite the fact that some linguists, following Bach 1981, use the term only for telic aspectual types ${ }^{2}$
} 
compatibility and interpretation with the variety of temporal adverbials. The question of the relation between these time schemata and the elements of meaning lexicalized in the verbs is not raised by Vendler. Dowty (1979: chapter 2) attempts to relate word meaning to aspectual classes by using lexical decompositions to represent the different aspectual classes. The decompositions are meant to capture certain regularities; for example, that particular verbs are often used in both activities and accomplishments (e.g. walk/ walk to the store; pound/pound the metal flat) and in both states and achievements (e.g. the ambiguity of many mental state verbs like recognize, understand, know). The decompositions are also meant to give a uniform representation for telicity (all involving a state predicate in the decomposition). However, predicate decompositions of this sort were not originally developed with lexical aspect in mind. They were first introduced by generative semanticists (Lakoff 1968, McCawley 1968)) to capture systematic morphological relations between classes of verbs and shared selectional restrictions and entailments between them, as in the following triad:

1. a. The soup is cool.

b. The soup cooled.

c. The chef cooled the soup.

These decompositions were introduced, then, to capture what might be called THEMATIC RELATIONSHIPS between uses of predicates, rather than aspectual relationships. It turns out that these decompositions are not appropriate for representing the Vendler classes: what emerges from section 3.8 of Dowty (1979) is that classes defined by decompositions do not have uniform aspectual properties and classes defined in aspectual terms do not have uniform decompositions. Although BECOME is given a temporal interpretation, CAUSE and DO are not. Even predicates defined by BECOME do not have uniform temporal properties, since BECOME is implicated in the class of singulary definite changes and in complex changes, which have different aspectual properties. The idea that decompositions do not yield aspectually uniform classes is foreshadowed in McCawley (1976) who shows that there are causative verbs in all aspectual classes (cf. also Levin 2000, Rappaport Hovav and Levin 2002; Levin and Rappaport Hovav 2005 and Van Valin and LaPolla 1997). In fact, although Dowty (1979) is about word meaning, the predicate decompositions fit into logical structures of sentences and the exact relation between the elements of meaning lexicalized in particular verbs and the logical structure of the sentence is never made completely clear.

One currently dominant approach to aspect (Arad 1998, Borer 2005, Ritter and Rosen 1998 and van Hout 2000) takes us further away from the study of the relationship between elements of meaning lexicalized in verbs and the aspectual classes they appear in. This is because on this approach verbs project freely into syntactic structures which themselves define and determine certain aspectual properties. In essence, any verb can project onto any aspectually defined syntactic configuration, so long as the meaning of the verb and the meaning encoded in the syntactic configuration are compatible, in a way never made explicit. Thus, this approach leaves one with the impression that verbs do not have any inherent aspectual properties. This, however, cannot be correct, if there is any notion of aspectual composition, with the properties of predicates corresponding to 
larger linguistic units derived compositionally from the properties of the head and the rest of the material in the VP.

Nonetheless, there have been attempts to figure out how particular components of lexicalized meaning determine certain aspectual properties of the event-denoting predicates into which they can be integrated. In this category fall the studies in Beavers (to appear, 2006), Dowty (1991), Erteschik-Shir and Rapoport (2004), Filip (1993/1999, 2004, this volume), Filip and Rothstein (to appear), Hay, Kennedy and Levin (1999), Kearns (2006), Kennedy and Levin (2002), Krifka (1989,1992, 1998); Tenny (1994), Wechsler (2004). They all look at the relationship between the aspectual property of telicity and some notion of measure (Tenny), scale (Fillip, Hay, Kennedy and Levin, Beavers, Wechsler), incremental theme (Dowty, Krifka, Rothstein), quantity criterion (Filip 2004b) or ordering criterion (Filip and Rothstein 2006) in the event structure. These terms are not all exactly equivalent, and this is not the place to compare them in depth. I will use the term scale in the exposition which follows, making clear what I mean below. Most of these studies do not take as their main goal the separation of those aspects of lexicalized meaning from those of the classes formed at the VP level. However, each has certain insights on this question. ${ }^{3}$

In this paper I will attempt to systematically address the question of what aspectually relevant properties are encoded in the meanings of verbs and the grammatical reflexes of these properties in the formation of larger event-denoting predicates (which I will refer to as 'aspectual composition') and argument realization. Relying heavily on the works cited above, I will lay out in section 2 what I consider the aspectually relevant lexical properties of verbs. This will, then, be a classification of verbs, and not event-denoting predicates corresponding to larger linguistic units. This schema classifies verbs along somewhat different lines than the traditional four-way Vendler classification, since, as we will see, many predicates just do not fit will into these category. In this section I also discuss certain generalizations concerning the kinds of information packaged into verb roots. All of the lexical distinctions described in this section have grammatical consequences which are relevant to aspectual composition. These grammatical consequences are illustrated in section 3 .

This leads us to the question of whether at the VP level we have just four homogenous aspectual classes. I will suggest that while it may be convenient to make reference to four aspectual classes at the VP level, at least the class of accomplishments is not homogenous with respect to internal temporal properties. I will illustrate this in section 4 . In the conclusion, I compare the lexical and compositional classes which emerge from my study with the traditional Vendler classes.

\footnotetext{
${ }^{3}$ Rothstein (2004, to appear) classifies verbs themselves as basically being states, activities, achievements and accomplishments. She, however, also seeks to isolate the basic components which determine these lexical classifications, and it is these components, rather than the classes themselves, which are important. I will stress in this paper that the components of meaning which determine the ways in which verbs enter into aspectual composition give rise to more than just four lexical classes. This is in fact similar to the conclusion reached by Rothstein.
} 


\section{Aspectually Relevant Lexical Properties of Verbs}

The most basic aspectual distinction is whether or not an event in the denotation of the verb involves change, i.e. whether a verb is dynamic or stative. Here I side with Dowty (1979), Filip (1993/99 and Verkuyl (1989), and most traditional aspectual descriptions (e.g. Comrie 1976), and not with Rothstein (2004; to appear), who assigns the feature [+change] only to accomplishments and achievements (for more on this, see section 4). As pointed out by Dowty, all dynamic predicates involve some kind of change and can therefore only be judged true at an interval, since at least two moments in time are necessary for the change to take place. ${ }^{4}$

While all dynamic verbs involve change, there is an important distinction between verbs denoting events of SCALAR CHANGE, such as warm, ripen, cool, fall and ascend, ${ }^{5}$ and those, such as play (in the sand) scribble (on paper), flutter (in the wind), exercise, tickle, writhe, scream, laugh, rain, etc., which denote events of NONSCALAR CHANGE.

Henceforth, I will refer to verbs denoting events of scalar change as SCALAR VERBS, and those denoting events of nonscalar change as NONSCALAR VERBS. This is a distinction which is implicit in many accounts, but has it has never, as far as I know, been isolated as the basis for a fundamental lexical-aspectual distinction. Nor have the ramifications of this lexical distinction been explored carefully. As will be made clear in section 3 , this distinction has ramifications for aspectual composition and also for principles of argument realization. Here I will elaborate on the nature of the distinction.

Verbs which denote events of scalar change are those which lexically specify a scale. A scale is an ordered set of values for a particular attribute. A scalar change is one which involves an ordered set of changes in a particular direction of the values of a single attribute and so can be characterized as movement in a particular direction along the scale. In the case of the verb warm, the scale is composed of ordered values of the attribute warm, and a warming event necessarily involves an increase in the value of [warm]. In the case of descend, the scale is composed of ordered values of an attribute something like [located height], and an event of descending necessarily involves a decrease in the value of this attribute. There are three kinds of scales recognized in the literature: property scales, path scales (scales of position along a path) and volume/ extent scales. Property scales are associated with change of state verbs such as lengthen, shorten, dim, open, close, widen etc. Path scales, which indicate the position of the theme along the path, are associated with verbs of directed motion, such as ascend, descend, enter, exit, come and go. Extent scales are associated with what are often called incremental theme verbs such as read, eat and build. In section 3, I will suggest that in most cases, the scale associated with incremental themes have a different status from the

\footnotetext{
${ }^{4}$ Dowty (1979) takes activities on the one hand and achievement and accomplishments on the other, to involve change, distinguishing between the two classes in terms of whether there is a definite or an indefinite change. A state may also need an interval to be judged true, as in the case of the simple position use of verbs of spatial configuration such as sit, stand and lie. So the implication is that a predicate which denotes an event involving change is judged true at an interval, but the implication does not work in the other direction.

${ }^{5}$ In Levin and Rappaport Hovav (1995) such verbs are described as those which select arguments which undergo a "directed change".
} 
other two kinds of scales, since the scale is not directly encoded in the verb, but rather provided by the entity in the denotation of the object of the verb.

The change lexicalized in most activities is nonscalar in nature. We suggested above that scalar change verbs lexically specify a simple attribute whose values can be ordered to form a scale, and the events in their denotation must involve change in a particular direction along this scale. In contrast, the change specified by many activity verbs are complex and involve a complex combination of changes, as in the case of most typical action verbs, such as run, jog, grimace, and scribble. Some activity verbs specify a sequence of a combination of changes, as illustrated in Dowty's (1979) discussion of the verb waltz (p. 171). While there is an inherent order to the steps of a waltz, one is not considered to be waltzing when going through a single sequence of three steps. So, with verb waltz, and many verbs of complex human activity, the events in their denotations are homogenous - and hence do not involve an ordered change - down to the relevant minimal units. ${ }^{6}$ Nonscalar verbs, then, typically differ from scalar verbs in two ways: they often involve a complex change and not a change in a simple attribute, and, in addition, the change entailed by these verbs is not an ordered one. ${ }^{7}$

Beavers (2006, to appear) suggests that all verbs of change are associated with a scale. He bases this assertion on the fact that, at least in English, any activity verb can appear with a scale-denoting result phrase, as in (2) and (3).

2. a. Max scrubbed the floor.

b. Max scrubbed the floor clean.

3. a. Cynthia ran.

b. Cynthia ran to her friend's house/herself ragged.

But, while the verbs in (2) and (3) can be combined with a scale, the scale is not lexically specified, as it is with verbs of scalar change. I suggest that while all dynamic verbs are potentially associated with a scale, (at least in English) with some verbs this is a lexical property and with other verbs this is not.[footnote: Another argument for distinguishing between scalar and nonscalar predicates, and not assuming that all verbs are associated with a scale, is that there are languages in which the association of a scale with nonscalar predicates is much more restricted than it is in English (Talmy 1985, 2000, Levin and

\footnotetext{
${ }^{6}$ In some cases, like waltz, it is homogeneity, but in some cases, like exercise there is no real homogeneity, as exercising does not necessarily involve the a repetition of exactly the same sequences. This is not the place to elaborate on this, however. The difference parallels the difference in the nominal domain between mass nouns such as wine and minestrone.

${ }^{7}$ There seems to be a generalization that changes that are typically predicated of animates are nonscalar in nature, while changes which take place in inanimates are very often scalar. I think this comes from the fact that human activities are typically complex, whereas a scalar change is simple in that it specifies a change in one attribute. People often have the intention of producing such simple changes in an entity, but changes that characterize the activities of animates are usually complex activities that involve a combination of many changes at once, which can then not be scalar in nature. Jackendoff (1996) makes a similar observation about incremental themes and offers a somewhat different explanation. He points out that volitional predicates are predicated of individuals rather than increments of individuals. Perhaps the two points are related.
} 
Rappaport Hovav 2006, among others). ] I will present evidence for this in section 3. Here I will mention a generalization which rests on the distinction between verbs which lexically specify a scale and those which do not. It is often claimed that when a scale is used with an explicit bound, the predication is telic, and when no explicit bound for the scale is provided the predication is an atelic one (e.g. Hay, Kennedy and Levin 1999). However, it appears to be the case that verbs that lexically specify a scale can have a telic interpretation even without an overt expression explicitly bounding the scale. Kearns (to appear) points out that verbs like increase, decrease and cool can have a telic interpretation even without an explicit bound. See also Rothstein (2004; to appear). This is seen in examples such as (4)

4. The prices will increase in three months.

It is true that activity verbs may be found in telic predications without a phrase indicating a bound, as in (5).

\section{John swam in three hours.}

However, (4) is different from sentences (5) in a very important respect. The latter is grammatical only if the scale and the bound required for the telic interpretation of the sentence are recoverable from context. For example, this sentence is ok if the speaker and hearer share the information that John swims for a set time each day. (4), in contrast, does not have to be contextualized in order to receive a telic interpretation. It is the lexicalized scalar change on its own, then, which is mainly responsible for the potential for a telic predication, supporting the distinction between verbs which lexicalize a scale and those which do not. Moreover, as Kearns (to appear) points out, when verbs like $\mathrm{cool}$ are used telically without an explicit bound, they may have the properties of an achievement (6a). When verbs like run are so used, they only have the properties of an accomplishment (6b).

6. a. The prices increased in three months (after a lapse of three months there will be some change in the prices) b. John ran in three minutes (spent three minutes doing a contextually specified amount of running.)

Among the scales which can be lexically specified by a verb, I will distinguish between two-point and multi-point scales (borrowing ideas from Beavers 2006, to appear). Twopoint scales have only two values to the attribute: being associated and not be associated with the attribute. In contrast, there are many values for the particular attribute lexicalized in a complex scale. The distinction is relevant for property scales and path scales. Extent scales cannot by their very nature be two-point and must be multi-point. For verbs associated with property scales this distinguishes between die and lengthen, corresponding to the property base being a contradictory property in the first case and a contrary one in the second case. So, John died is true just in case John went from having the property of not being dead to having the property of being dead. In contrast, The river widened is true if there is any increase in the value of [wide] associated with the river. 
For spatial path scales this yields the difference between reach the summit, with a two point path, and ascend, with a complex path. We reached the summit is true just in case we went from not being at the summit to being at the summit while We ascended the stairs is true just in case our location along the path represented by the stairs increased in any value. In what is perhaps the unmarked case, there is a homomorphic mapping between the event and the scale associated with the event (Beavers to appear, Filip 1993/99, Wechsler 2004). When this holds, an event described by a verb with a twopoint scale will be punctual, since the transition from being associated with the property and not being associated with the property takes place at two adjacent moments in an interval. An event described by a verb specifying a complex scale will be durative, as the change is characterized by multiple changes in the value of the attribute.

Two-point scales are inherently bounded and this makes the verbs associated with them telic (and punctual). For multi-point scales, we need to distinguish between those which have a bound and those which do not, corresponding to the difference between what have been called closed scale and open scale gradable adjectives (Hay 1998; Kennedy and McNally 2005; Rotstein and Winter 2004; Wechsler 2005). This yields the difference between flatten, related to a closed scale gradable adjective, and lengthen, related to an open scale adjective, and between walk to the store and walk toward the store, the former having a bounded path and the latter an unbounded path.

The most common kind of scale lexicalized in a verb is a property scale. Often such a scale corresponds to a nonderived adjective, and the verb lexicalizing the scale denotes a change along the scale in the denotation of the adjective, that is, a change in the value of the attribute for the theme of the verb. The largest class of verbs with lexicalized scales is the class of change of state verbs, such as lengthen, widen, smoothen, flatten, etc., many of them deadjectival. ${ }^{8}$ Since the class of gradable adjectives is much larger that the class of nongradable adjectives, the class of what are often called (deadjectival) degree achievement verbs (more aptly called 'gradual completion verbs' in Bertinetto and Squartini 1995), such as cool and widen, is much larger than the class of deadjectival true achievements (such as die) ${ }^{9}$. In English, the class of verbs which lexicalize a path scale is much smaller, probably due to the dominant kind of lexicalization pattern, in the sense of Talmy (1985), which involves the conflation of manner with the verb and not path with the verb. ${ }^{10}$ Another reason for the smaller number of verbs which can lexicalize a path is the relatively small number of properties a path can lexicalize. These properties include direction, boundedness and diecticness, each with a small number of instantiations (see, for example, the discussion in Talmy 2000). In comparison, there are many more state properties that can be lexicalized. Among the verbs which lexicalize a path scale, there are which lexicalize a two point path, as exit, enter, leave, reach etc. and there are those

\footnotetext{
${ }^{8}$ Of course, many change of state verbs, such as break, shatter and homogenize, are not deadjectival. The difference between these verbs and verbs like flatten seems to derive, at least to a large degree, from whether or not the state can be conceived as a natural state or one that is necessarily the result of a previous event. See also Dixon (1982) and Koontz-Garboden, A. and B. Levin (in press).

${ }^{9}$ In fact, it is unclear whether there are any other candidates for deadjectival achievements, and it is not entirely clear that die is deadjectival either.

${ }^{10}$ Rappaport Hovav and Levin (2006, to appear) claim that verbs can either lexicalize a manner or a path, and that this boils down to a constraint on verbs lexicalizing either a scalar or a nonscalar change.
} 
which lexicalize a multi-point path, such as ascend, descend and soar. Verbs which lexicalize a complex bounded path are verbs such as traverse and cross. ${ }^{11}$

When we look at the argument realization properties of verbs that occur with scales, it emerges that verbs which appear with volume/extent scales (traditional incremental theme verbs) exhibit properties which are different from other scalar verbs. I will suggest that this is because the scale which occurs with these verbs is provided by the referent of the direct object and not by the verb itself. However, I need to present some linguistic evidence for the difference between lexicalized and nonlexicalized scales in order to be able to do this. I will do this in section 3 .

Some verbs lexicalize what might be considered more than one event, and verbs differ in the temporal relation between these subevents. For example, the verb throw (and other verbs of ballistic motion (Pinker 1989)) entails both the release of an object while setting it in motion, and the object's traversal of the path.

7. a. John threw the ball into the basket.

b. \#John threw the ball, but it didn't go anywhere.

Clearly, the activity that the agent engages in and the change the theme undergoes are not coextensive. In contrast, verbs like $d r a g$, lexicalize the activity the agent engages in, and a simultaneous and coextensive change in the theme.

\section{I dragged/schlepped/pulled the piano out of the room}

This difference between throw and drag is a lexical one, having to do with the temporal relation between the subevents in the denotation of the predicate. Krifka (1999) describes verbs such as drag as lexicalizing and event-to-event homomorphism. This distinction has received very little attention in the literature and does not correspond to any commonly-discussed aspectual distinction. However, it does have to do with the internal temporal constitution of events, and as I will show in section 3.3.1, it has consequences for aspectual composition.

In the next section I look at grammatical reflexes of some of the lexical properties mentioned in this section.

\section{Grammatical reflexes of lexical aspectual properties}

\subsection{Scalar Verbs vs. Nonscalar Verbs}

\footnotetext{
${ }^{11}$ For verbs like cross, there are really many more options, since we can have sentences like John crossed the border, The train crossed the border, and John crossed the desert, all with different modes of aspectual composition (Dowty 1991, Jackendoff 1996, Krifka 1998) . All verbs which select a bounded path have the path bounded by the bound of the reference object (Jackendoff 1983), or the ground (Talmy 2000), as in exit the room, enter the room, traverse the floor and cross the desert. Thus, they select NPs and not bounded PPs. There are no verbs which are like go, except that they select a bounded PP.
} 
Since two-point scale verbs like reach and notice are always telic and punctual, they differ from verbs like play and cry and also widen and dim, which sometimes enter into telic predications and sometimes atelic predications.

9. a. The crack in the wall widened for three days, before we filled it. (atelic)

b. The crack in the wall widened a centimeter in a day. (telic)

10. a. I cried for five minutes. (atelic)

b. I cried myself to sleep in five minutes. (telic)

However, I have suggested that play and cry do not lexically specify a scale, but widen and do. Therefore, while "a centimeter" in (8b) introduces a bound to a lexically specified scale, "to sleep" in (9b) introduces a bounded scale to a verb which has none to begin with. I suggest that there are grammatical reflexes to the fact that the scale with widen is lexically specified while the scale with cry is not. One was mentioned in the previous section: verbs of scalar change can be used telically without an explicit measure phrase and without a contextually recoverable scale, where verbs of nonscalar change cannot. In this section I look at some other pieces of evidence.

In general there appears to be a constraint that a VP cannot contain two phrases with the function of measuring out, or delimiting the event (Filip 2004a, Goldberg 1991, Levin and Rappaport Hovav 1995, Simpson 1983, Tenny 1994,). Result XPs are scaledenoting; they either introduce a scale or provide a further specification of a lexically specified scale (Goldberg 1991; Levin and Rappaport Hovav 1995; Wechsler 2004, among many others). Therefore, a verb with no lexically specified scale can appear with a variety of results.

11. a. We steamed the clothes dry.

b. We steamed the clothes clean.

c. We steamed the clothes stiff.

12. a. Cinderella scrubbed her knees sore.

b. Cinderella scrubbed the dirt off the table.

c. Cinderella scrubbed the table clean.

In contrast, verbs which have lexically specified scales, whether or not they are used in a telic predication, are very restricted in the kinds of resultatives they can appear with. These verbs can only appear with result XPs which either specify the bound of the scale or elaborate on a lexically specified bound for the scale. They may not appear with a scale not related to the lexically specified scale. This is illustrated in (13). In (a-d) the result XPs provide further specification of the lexically specified scale, while the sentence in (d) involves a newly introduced scale.

13. a. We froze the ice-cream solid

b. The walnut broke apart.

c. The chocolate melted into a messy goo. 
d. Then the biologists dimmed the room to the level of starlight ... www.findarticles.com/p/articles/mi_m1134/is_2_112/ai_98254950 - 22k (Thanks to Hana Filip)

e. *We dimmed the room empty.

We find the same effect with verbs which lexicalize a path scale, which cannot appear with result state XPs. (The sentences below are ok if the APs are interpreted as depictives, of course.)

14. a. *Willa arrived breathless. (Levin and Rappaport Hovav (1995:55 (58))

b. *Sharon took/brought Willa breathless. (L\&RH 1995:56 (61))

But they can appear with goal phrases that further specify the path, or provide a bound to the path.

15. a. We arrived at the airport.

b. The leaves fell to the ground.

Verbs which lexicalize a scale, whether bounded or not, cannot appear with a nonsubcategorized DP followed by a result XP, as in (12d) above (Levin and Rappaport Hovav 1995), since sentences like these involve two scales, one from the verb, here dim, and another from the result XP. This last scale is predicated of the nonsubcategorized DP.

The second motivation for saying that verbs which lexicalize scales are grammatically different from verbs without lexicalized scales is more speculative. Rappaport Hovav and Levin $(2002,2004)$ and Levin and Rappaport Hovav (2005) have stressed that the theme of a change of state verb is different in a number of related ways from other kinds of direct objects, even those with a number of Dowty's (1991) patient proto-role entailments. First, they systematically resist object deletion (16). Second, they resist entering into any construction in which the normal direct object is "usurped" by another DP (17 and 18).

16. a. All last night we dimmed *(the lights in the house).

b. All last night we cooled *(the room with the air-conditioner.)

c. All last night, Cinderella scrubbed.

17. a. *We cooled the people out of the room with the air-conditioner on too high.

b. *We dimmed the room empty.

c. Cinderella scrubbed her knuckles bare.

18. a. *The air-conditioner in our office outcooled the air-conditioner in the next office.

b. *Our stage-hand outdimmed your stage-hand.

c. Cinderella outscrubbed her stepsisters. 
In previous work Levin and I (Rappaport Hovav and Levin 1998, Levin 2000) suggested that this pattern follows from the fact that change of state verbs denote complex events and the rules for argument realization, being sensitive to event complexity, require that the theme of the change of state be realized. Here I would like to suggest an alternative, though perhaps related, explanation for the data. Suppose that scales require that the participant whose property is measured by them be overtly realized. It follows, then, that for verbs which lexicalize a scale, the DP of which the scale is predicated must be expressed. From this it will follow that change of state verbs cannot leave their object unrealized. In addition, since most of the constructions in which the object is replaced by a nonsubcategorized object involve the introduction of a new scale, these constructions are ruled out with change of state verbs by the constraint against more than one scale in a clause. The reason I prefer this account to the account based solely on event complexity, is that it is extremely difficult to arrive at an independently motivated definition of event complexity which will single out just the class of change of state verbs. It is not clear what independently viable criterion makes a verb like break or cool denote a complex event but not mow or comb. Even in terms of entailments, the objects of, say, mow or $\mathrm{comb}$, undergo a change just as the object of cool or dim. But the former do not behave in terms of argument realization like the latter. I assume that it is the scalar nature of the change which is responsible. ${ }^{12}$

With this insight in hand, we may return to the class of incremental theme verbs, previously characterized as verbs with extent/volume scales. It is very striking that such verbs pattern with activity verbs with respect to the diagnostics I laid out immediately above. (19a) shows that a verb like read can omit the direct object (cf. 16 above). (19bd) illustrate the possibility of adding a direct object and a scale which are not selected by the verb (cf. 17 above).
19. a. John read.
b. John read us all to sleep.
c. John read his eyes sore.
d. John outread Mary.

Why should this be? I suggested that volume/extent scales are not actually lexicalized in the verb, but are rather provided by the direct object argument. This means that many verbs which are traditionally considered incremental theme verbs may have an incremental theme interpretation in particular contexts, but are nonetheless not lexically required to take incremental themes. As an example, consider a verb like read. I suggest that read is not lexically associated with a scale (see also Rothstein 2004). Notice that while the scale associated with a verb like cool specifies the change in the theme argument, read does not entail a change in the denotee of its direct object, but rather in that of its subject. If you want to know if a road sign was read by someone, you don't check anything about the road sign, but you do check something about the reader. The

\footnotetext{
${ }^{12}$ There have been tests offered for event complexity, such as the ambiguity of almost and again. However, it seems that these test for result states rather than event complexity (see section 4.1). Constraints on space prevent me from elaborating further on this issue.
} 
change in the subject denotee is not scalar in any sense. It is true, however, that when the object is of the appropriate sort, it will be understood as incrementally involved in the event. But, as shown by Verkuyl (1989) and Jackendoff (1996), and discussed by Mittwoch (1991), the meanings of many verbs which can include an incremental process in their denotation do not change if the change is not incremental. This is true for a verb like read which can be used with scanners that can read a sequence of numbers nonsequentially in an instant (20a), and for reading a single letter (20b)

20. a. The scanner read the bar code.

b. Eye doctor to patient: Read this letter on the bottom of the chart.

There are, however, incremental theme verbs which do lexicalize a change in the theme argument. Such a verb is eat, which entails that theme is ingested. Syntactically, eat patterns with read and other activity verbs, not with verbs of scalar change. Notice, however, that, as Dowty (1991) and Jackendoff (1996) point out, the verb does not change its meaning if the consumption is accomplished holistically, rather than incrementally, as when a person eats a raisin in a single swallow. Therefore, the verb does not lexically require incrementality. In fact, eat lexicalizes a change in both the subject denotee and in the object denotee. The change specified for the subject denotee is not scalar in nature and, as we have just seen, the change specified for the object denotee is not necessarily scalar. If we return to the properties which characterize scales mentioned in section 2 above, we see that verbs such as cool and ascend do indeed lexicalize a scale since they specify an attribute with an ordered set of values. But verbs like read are provided with a scale by particular DP objects, but the scale is not part of the lexical meaning of the verb. Notice also, in this regard, that when we look at the argument realization patterns which we have attributed to scalar structure, there is no difference between what Krifka (1998) has called incremental theme arguments (arguments of verbs such as read), and what he calls strictly incremental theme arguments (arguments of verbs such as eat). They all pattern like the arguments of nonscalar verbs. See also Filip (this volume).

It should be pointed out that eat the sandwich is certainly different in this respect from push the wagon. That is, push never affects the direct object incrementally, and this is a lexical property of the verb push. Therefore, unlike eat, a verb like push must be lexically specified to be nonscalar in nature. In Krifka's (1998) terms, the thematic relation of the object of push cannot have the mapping to subobjects property (MSO), while the verb eat optionally, and probably in the unmarked case, does. However, as also stressed by Filip (this volume), having an incremental theme and being lexically associated with a scale do not necessarily go hand in hand. In the case of the incremental reading of eat, the scale is provided by the physical extent associated with object denoted by the direct object.

The same will be true for many other verbs, such as sing, which are typically considered incremental theme verbs. The verb does not have to appear with an object that provides an incremental scale, as in the following examples: 
21. a. Melisma occurs when a singer sustains a note, but switches pitch within the same register while singing that note, often several times. (Wikipedia)

b. How to sing high notes. (chanteur.net/contribu/cKMaigus.htm)

The most common complements that appear with sing will provide the activity of singing with an incremental structure, but the verb lexicalizes a change in the subject and only with the selection of the appropriate object does the activity receive an incremental structure. Correspondingly, sing appears with a wider range of result XPs than those that are allowed by verbs with a lexically specified scale. A quick Google search yielded the following among the first 60 hits for sang us:

22. a. My mother often says that she sang us through our childhoods. (home.wlu.edu/ hourenk/univ203/bio.html)

b. It was so beautiful and you captured our feelings, gave us wisdom, humor, love and sang us into bliss. (gailchasin.com/Weddings.htm)

c. D. Kimm spoke for Montréal, her French-accented English lilt sentences sang us into a performance mode (poetry.about.com/od/livepoetry/a/canadasummit05_3.htm)

\subsection{Two point scale verbs vs. multi-point scale verbs}

There has been much discussion in the literature of whether or not there is a real grammatical distinction between accomplishments and achievements, that is, whether or not durativity is grammatically relevant (Verkuyl 1989, Tenny 1994, Mittwoch 1991). I have taken the position that there is a real lexical difference between verbs that are associated with a two-point scale and those which are associated with a multi-point scale, corresponding to the distinction between achievements and accomplishments. I will show, along with Beavers (to appear), (Filip 1993/99), Filip and Rothstein (2006), Mittwoch (1991) and Rothstein (2004), and contra Verkuyl (1989) and Tenny (1994), that this is indeed a grammatically relevant distinction. When the predicate is associated with a multi-point scale (volume/ extent scale, gradable property, incremental path), in the past tense use of the verb, unless there is something in the context which specifies otherwise, some change along the scale is entailed, but change along the entire scale is only inferred by conversational implicature, governed heavily by pragmatic conditions. See also Fillip and Rothstein (2006), Filip (this volume). ${ }^{13}$

23. incremental theme verbs with a physical extent scale
a. I mowed the lawn, but not all of it.
b. I read the newspaper, but never finished.
c. I studied the file, but never got to the end.

\footnotetext{
${ }^{13} \mathrm{With}$ all of these verbs, there is the issue of distinguishing between contextual vagueness as to what constitutes completion (i.e. being completely empty, completely clear etc.) and a real atelic reading. I am currently not quite sure how to do this, but my impression is that if it is possible to say I filled something even if it is not completely full, and that this is due to contextual determination of fullness, then this would not be followed by I filled it some more. Therefore, I assume that (24d) is a case of atelicity.
} 
d. I perused the list, but stopped before I got to the end.

e. ?I ate the sandwich but didn't finish.

f. ??I copied the manuscript but didn't finish

g. ??I memorized the list, but not all of it.

Notice, that (23 e-f) are considerably worse than the others. Filip and Rothstein (2006) argue that verbs which yield a VP that freely alternated between and atelic and a telic interpretation when combined with quantized incremental themes are what Krifka (1998) calls incremental theme verbs, whereas verbs which are what Krifka calls strictly incremental theme verbs consistently yield telic VPs when combined with quantized incremental theme arguments. But the verbs in (23f-g) are not strict incremental theme verbs, since one and the same object token can be subjected to a given event type more than once.

24. "degree achievement verbs" with a gradable property scale

a. If you put the tomatoes out on the porch, the sun will ripen them a bit (at least enough to make them edible.)

b. That acne medication helped clear her face, though she still has some pimples.

c. This board is too rough to use, but if you sandpaper it, we may be able to smooth it just enough so that we can use it.

d. The pastor had a jug of blue water and an empty glass. He filled the glass a bit and asked if it was full, the crowd said no. Filled it some more...Not full...Filled it overflowing and set it down. Then he used it to illustrate what happens as you go through your day 'ministering' to others. (infertilearocat.blogspot.com; thanks to Beth Levin)

25. change of location verbs with a multi-point path scale

a. I threw the ball to Mary, but it didn't get there.

b. We launched the rocket to the moon, but it blew up before landing.

c. We sent the boys to grandmother, but they got lost on the way.

In contrast, if the verb lexically encodes a two-point scale, the full transition is entailed.

26. a. I reached the summit.

Entails b. I was at the summit.

27. a. John died, (*but not completely)

Entails: b. John is dead.

28. a. I found my keys.

Entails b. I knew where my keys were.

In this regard, the distinction between the two-point scale and the multi-point scale is more important than the distinction between open and closed scales. The aspectual 
properties of verbs associated with gradable closed scales do not differ to a large degree from the ones associated with a gradable open scale. That is, even if the scale associated with the verb has a lexical bound, as in (24b-d) above, the past tense use of the verb still does not entail that the bound of the scale was reached. Some people find examples like (29) below odd.

29. I emptied the tub but not completely.

Kearns (to appear) points out that closed scale gradable adjectives like empty lexicalize a maximal value, in contrast to similar closed-scale adjectives like clear which do not. This is probably the source of this unease. However it is striking that it is quite easy to find examples like the following:

30. I empty the dishwasher a little and do one set... empty it some more and do one more set...

(caroleingram.blotspot.com/2005_10_01_caroleingram_archive.html)

This is completely impossible with true achievements, like reach:

31. *I reached the summit a bit and then continued on my way to the summit

This is true, even though reach, like other achievement verbs, can appear in the progressive to cover the time preceding the actual punctual transition to the goal, as in The train was reaching the station, when it hit the obstacle.

To summarize, verbs which lexicalize a multipoint scale entail some change along the scale in the past tense, but not the maximal change, even if there is such a lexicalized maximal change. In the case of true achievement verbs the minimal change is also the maximal change, in a completely trivial sense.

\subsection{Temporal relations between events}

In section 2 above, I suggested that when a verb entails two subevents, the verb may specify something about the temporal relation between theses subevents. In this section, I point out a number of grammatical reflexes of the distinction between subevents which are temporally dependent and those which are not.

\subsubsection{The interpretation of the preposition to}

There are a variety of interpretations for the preposition to in English. Most often, the object of the preposition marks the endpoint of a bounded path and so the preposition implicates the existence of such a path. A path is usually integrated into an event structure in such a way that a theme traverses the path, as in John walked to the store, the ball rolled to the wall, Mary sent the boys to school. But while there is a traversal of the path and the path is indeed bounded by the entity denoted by the object of the 
preposition, whether or not the theme necessarily traverses the entire path and reaches the bound of the path depends on the particular verb:

32. a. John ran to the store

b. John rolled the barrel to the store.

c. John drove the car to the store

d. The cup fell to the floor.

e. John dragged/lugged/schlepped the box to work.

In all of these cases the theme must reach the endpoint of the path. This is not the case in the following sentences:

33. a. I threw the ball to Mary (but aimed badly and she didn't catch it.)

b. I threw the ball to first base (but didn't throw hard enough and it didn't reach first base).

c. I sent the package to France (but the ship sank and the package never arrived.)

d. We launched the rocket to the moon (but it blew up before it got there).

What can we attribute this difference in interpretation to? If we looked only at examples in (33) we might be led to believe that there is some kind of ambiguity in the semantics of the preposition, since these sentences are compatible with an interpretation in which the theme traverses the entire path and one in which the theme does not. However, the examples in (32) allow only the interpretation where the theme traverses the entire path. I suggest that this follows from the lexical semantics of the verb. Krifka (1999) suggests that there is an event-to-event homomorphism for verbs like drag, in which the dragging event and the motion event must proceed and unfold together. In the terminology of Levin and Rappaport Hovav (1999) and Rappaport Hovav and Levin (2001), the events of dragging and traversing the path are temporally dependent. In contrast, the verbs in (33) do not have this property: these are Pinker's (1989) verbs of ballistic motion (with send being the possessive counterpart to verbs of ballistic motion). For example, in $(33 \mathrm{a} \& \mathrm{~b})$, the event of throwing is not homomorphic with the event of the theme, in this case, the ball, traversing the path.

So, we can maintain that the preposition to marks the endpoint of a bounded path in all cases and the entailment of complete traversal or the absence of such an entailment follows from the lexical semantics of the verb, which specifies the relation between the subevents. $^{14}$

\subsubsection{Icelanding case marking}

\footnotetext{
${ }^{14}$ Beavers (2006) points out that the use of to implies that the theme has the potential of reaching the goal so that if a clear barrier separates John and Mary one cannot say John threw the ball to Mary.
} 
Svenonious (2005) claims that there are some direct objects in Icelandic which take accusative case and others which take dative case. The dative case is used "when the verb denotes a connected pair of events which do not perfectly overlap." (2005:8):

34. a. They carried the hay (acc) up on the wagon.

b. They threw (dat) the hay up on the wagon.

Carry in (34a) is similar to drag in that the activity of carrying performed by the agent is necessarily coextensive with the change of location that the theme undergoes. the movement of the hay and the movement of the agent carrying the hay must be coextensive and accusative case is assigned. In (34b), the release of the hay from the thrower and the traversal of the hay on to the wagon are not temporally coextensive, and the direct object is marked with dative case. Thus, the distribution of case marking in Icelandic appears to be sensitive to the distinction we have been making concerning the temporal relations between the subevents of a complex event.

\subsubsection{The distribution of fake reflexives}

Another grammatical reflex of the temporal relation between events is the distribution of fake reflexives in resultatives in English. It is well-known that for some intransitive verbs, a result XP can be predicated directly of the subject, but for other intransitive verbs, a fake reflexive is required (Simpson 1983, Levin and Rappaport Hovav 1995). Levin and Rappaport Hovav (1999) and Rappaport Hovav and Levin (2001) suggest that when the event specified by the verb and the change encoded in the result XP are not necessarily temporally dependent, the fake reflexive is needed, and when they are necessarily temporally dependent, the fake reflexive is usually not needed. In naturally occurring texts, verbs like wiggle and pull in combination with the result AP free may appear with and without the reflexive. Analysis of the contexts in which these different uses of the resultative appear indicate that the reflexive is used when it is clear that a punctual becoming free follows a durative event of wiggling or pulling, while the result $\mathrm{XP}$ without the reflexive is used when the action denoted by the verb proceeds in tandem with the becoming free.

\section{He wiggled/jerked/pulled/yanked/wriggled (himself) free}

Why should temporal independence require the fake reflexive? Recall that in section 3, I suggested that a DP denoting an entity which a scale is predicated of must be grammatically realized. Now, if the activity the subject is engaged in is not coextensive with the scalar change represented by the result XP, then, strictly speaking, this DP cannot have the scale represented by the result XP predicated of it. Therefore, another DP, coreferential with the subject DP, must be introduced. ${ }^{15}$

The following kind of sentence may call our analysis into question:

\footnotetext{
${ }^{15}$ The distinction between temporal dependence and independence illustrated here is not completely lexically determined, and the factors which do determine this need to be scrutinized more carefully.
} 
36. Gosalyn did the Macarena as she danced herself across the floor. http://www.geocities.com/televisioncity/set/7910/dwdseasonfinale.htm

Here the events are necessarily temporally dependent (the dancing and the traversal of the floor go hand in hand), but the use of the fake reflexive is allowed. In Levin and Rappaport Hovav (1999) and Rappaport Hovav and Levin (1997), it is argued that examples such as (36) above should normally be ruled out by a Gricean maxim of quantity, much in the way periphrastic causatives normally do not express direct causation (McCawley 1978). Since the situations describable by the sentences without the reflexive are a subset of those with the reflexives, the use of the sentence without the reflexive is more informative than the use of the sentence with a reflexive, and, all thing being equal, should be preferred. There are specific pragmatic effects of the use of the self construction, when it is not strictly required by the grammar. Boas (2003:242) calls this the "perspectivizing -self", and shows that in these cases the use of the reflexive serves to portray the event "from a perspective that describes the agents' attitudes and emotions towards their movement, and usually their body". Levin and Rappaport Hovav (1997) show that in naturally occurring examples of this sort, the self phrase often contains a phrase modifying the body, highlighting the mind/body split here.

37. a. Domina implied that her hunger was so debilitating that she could hardly crawl her sleek self across the kitchen floor. (J.R. Hulland, An Educated Murder, St. Martin's, New York, 1986, p. 156)

b. Then, without another word, he withdrew from the kitchen and sauntered his Bermuda-shorted self through the front door. (D.M. Davidson, Killer Pancake, Bantam, New York, 1995, p. 63)

Crucially, when there are temporally dependent events with inanimates, this kind of splitting is impossible:

38. a. The door creaked (*itself) open.

b. The gate swung $(*$ itself) shut.

c. The bottle broke (*itself) open.

d. The rope pulled (*itself) loose.

\subsection{Interim Summary}

What emerges from this section is that there are reasons to draw lexical aspectual distinctions which are different from the distinctions drawn by the Vendler classification, a point I return to in the conclusion. However, the Vendler classification may be appropriate for compositional aspect, that is, aspect determined at the VP level. My impression is that in terms of the external temporal contour, we can indeed distinguish between these four classes. However, when we look at the internal temporal structure of accomplishments, we find that they constitute a rather heterogenous class. This is because there are many ways in which the event can get its incremental structure, a fact not fully acknowledged in current literature. In the next section I look at the internal temporal structure of a variety of accomplishments and show that there is indeed no uniform internal temporal structure to all accomplishments. It will emerge that the 
internal temporal structure of different kinds of accomplishments is determined by a variety of factors, including lexical and nonlexical factors.

\section{Against a Uniform Temporal Analysis for Accomplishments}

The idea that accomplishments can be given a uniform internal temporal representation has its roots in Dowty (1979), where accomplishments are analyzed as complex events with a causing subevent and a resulting change of state In many recent analyses accomplishments are still considered complex events (e.g. Parsons 1990, Rappaport and Levin 1998, Rothstein 2004). Rothstein (2004) argues further that all accomplishments have the same internal temporal structure. In particular, accomplishments involve an event-to-event mapping, with an extended BECOME event (an event of change), that runs simultaneously with an activity subevent. The role of the event of change is to structure the activity event, imposing on it an incremental process. There is a mapping function between the events and the events are cotemporaneous. Here I will argue, in two stages, against the view that all accomplishments have the same internal temporal structure. First, I will argue that not all accomplishments involve a BECOME event. Then I will argue that even when there are two subevents, the temporal relations between the subevents are not always the same, although this has, in effect, been shown in section 3.3.2. above. Furthermore, I will argue that the incrementality of an accomplishment does not necessarily derive from the change the theme undergoes.

\subsection{Not all accomplishments involve a BECOME event}

The class of activity (nonscalar change) verbs which may be associated with an extent/volume scale, providing a possible bound for the event denoted by the verb and imposing an incremental interpretation on the predicate has already been mentioned. Rothstein argues that in examples like (39) below, the predicate read Little Women is associated with a BECOME event, corresponding to the book becoming read, which imposes the incremental structure on the activity of reading (pp. 109-111).

\section{My daughter read Little Women.}

I will bring two kinds of evidence that read a book does not have a BECOME event. The first is really evidence that the direct object of the verb is not an affected object. Rothstein (2004:139) argues that the argument of the BECOME event is the affected theme, the argument to which the action is done. The only reason this may be crucial to the analysis, is that being an affected theme can be the basis for assuming that the theme is also the theme of a BECOME event. However, as already mentioned above, in the case of read, peruse or memorize, if there is an affected participant, it is the subject. The following is taken to be a diagnostic for an affected entity (Jackendoff 1987, 1990).

40. \#What we did to the road sign/to the letter at the bottom of the chart was read it.

The second, more important, argument is that verbs like read, even on their telic reading, are not associated with a result state, which all predicates assumed to involve a BECOME 
event should have. Verbs such as read and other information ingestion verbs such as study and peruse do not pass any of the tests which have been offered to probe the existence of a state predicate. One such test involves the adverbial again. It has been claimed that sentences with verbs which lexicalize a result state are ambiguous with the adverb again. In (41a) below, for example, there is a reading in which the door had been open and I caused the door to be in this state once more (though we do not know if it had been opened by anyone before). The other reading is of course one in which there were two events of door-opening. Transitive verbs which do not lexicalize a state do not show this ambiguity. I tickled my daughter again can only mean that there were two events of my daughter having been tickled. The verbs in (41) all clearly involve a lexicalized result state. In contrast, the verbs in (42) are traditional incremental theme verbs, and they do not show this ambiguity.

41. a. I opened the door again (ambiguous)

b. I closed the window again (ambiguous)

c. I filled the jar again (ambiguous)

42. a. I read the book again (not ambiguous)

b. I scanned the book again (not ambiguous)

c. I perused the article again (not ambiguous)

Another test involves the durational time adverbial for $X$ time. Sentences with verbs which lexicalize a reversible result state, have a reading in which the time adverbial modifies not the amount of time the action denoted by the verb was taking place, but rather the amount of time the result state has held. Sentences with verbs which do not lexicalize a result state do not have this interpretation. I tickled my daughter for three minutes only means that I spent three minutes tickling my daughter. Crucially, verbs like read pattern with verbs like tickle.

43. a. I opened the door for two minutes. (state lasted two minutes)

b. I put the book on the shelf for two minutes. (state lasted two minutes)

c. I inflated the tube for two minutes. (state lasted two minutes)

44. a. I read the book for two minutes. (spent two minutes reading the book)

b. I perused the document for two minutes. (spent two minutes perusing the document.)

c. I delivered the sermon for two minutes (spent two minutes in sermon.)

Related to this is the possibility of using still and the related adjective or adjectival passive. Kratzer (2000) argues that still is possible with the adjectival passives related to verbs which lexicalize a reversible state.

45. a. The book is still open

b. The book is still on the table

c. The tube is still inflated 
46. a. *The book is still read.

b. *The poem is still scanned.

c. *The article is still perused.

Rothstein suggests that the change the book undergoes when being read is that of 'becoming read'. But this would not distinguish the object of read from the object of any activity verb: if I tickle my daughter, we can say that my daughter has 'become tickled', but tickle would not be classified by Rothstein as a [+change] verb. In fact Rothstein translates the feature [+change] into something like 'naturally heads a telic VP' (p. 183). Unless some independently established criterion, besides 'naturally heads a telic VP' is offered, then the feature [+change] does not really explicate the difference between those predicates which naturally occur in a telic VP and those that do not. I suggest that it is not the feature [+change] which determines this, but rather the feature of scalar change.

It is true that there is a basic difference between tickle and read, which is related to the fact that the nature of the direct object affects the aspectual properties of the VP headed by read, but not of the VP headed by tickle. That is, read can take an incremental object, but tickle cannot. As mentioned earlier (section 3.1), this corresponds to Krifka's (1998) mapping to subobjects property which may hold of the object of read but may not hold of the object of tickle. I would suggest that this is the lexical property, not the feature [+change], which distinguishes between the two types of nonscalar predicates. It is because of this that the object of read may supply the verb with a scale, while the object of tickle cannot.

Is it the case that all incremental theme verbs do not have a result state on their telic readings? I think not. I think it depends on what the change is that the verb specifies. As we have seen, for verbs like read, the verb does not specify any change in the direct object denotee. The change in the subject denotee is not an incremental one. But consider a verb like comb. It does involve a change in the entity denoted by the direct object. I don't think it lexically entails a scale, and indeed, in terms of its argument realization patterns, it behaves more like nonscalar verbs than like scalar verbs. But as many have noted (e.g. Tenny 1994), there is an implicit scale, provided by the surface that is combed, usually a head or a wig. Since comb lexicalizes a physically perceptible change in the surface combed (though it is not a scalar change), when all of the relevant part of the head has undergone this combing we have a reversible result state of being combed. That is why you can get her hair is still combed etc. But the verb allows the omission of its object because the change lexicalized is not a scalar one.

\subsection{Complex events:}

We have just seen that there are accomplishment predicates which cannot plausibly be analyzed as being composed of two subevents. Turning now to accomplishments with two isolatable subevents, the question is whether these all have the same internal temporal structure. Scrutiny of a range of accomplishment types reveals that they do not. In particular, it is not the case that the two subevents are necessarily contemporaneous. 
In sections 2 and 3 we examined cases where the verb itself determines the temporal relation between the two subevents. So, for verbs of ballistic motion, the activity encoded in the meaning of the verb is not coextensive with the traversal of the theme over the path. Rather, they involve a punctual event followed by a durative event of a path traversal:

47. a. Ronaldo kicked the ball into the net.

b. Michael Jordan threw the ball into the basket.

As soon as the ball is released from your hand, you can say: I have thrown the ball. So, the verb throw is punctual. The change lexicalized is something like "under control of agent" to "not under control of agent" (Beavers 2006). It seems to be the case that the characteristic motion of the body is not necessary, but only implicated, since machine can also throw balls. Therefore, it is only the release which is strictly lexicalized. In (47a) above, the punctual release is followed by a durative telic event, a traversal of the theme over a bounded path. The entire event seems to count as an accomplishment since it is telic and durative, but the two subevents are not cotemporaneous and the role of the second subevent is not to impose an incremental process structuring the first subevent. The verb lexicalizes both the punctual nature of the change and also the temporal relations between the event of throwing and the event of traversing the path.

We contrasted verbs like throw with verbs like pull, in which the two events are necessarily cotemporaneous. We have a durative activity simultaneous with a durative traversal of a path: this is something which is lexically specified by the verbs.

48. a. Drag/carry/lug/schlep/tug/pull the books to school

b. Drive the car to school

Here the activity carried out by the agent is lexically specified to continue during the traversal of the path.

A point which I think has never received attention in the literature is that verbs like throw, which lexicalize a punctual release and entail the traversal of a spatial path are aspectually atypical in certain ways. As already mentioned, in a traditional aspectual classification sentences like those in (45) would be considered accomplishments: they are durative and telic. The preposition into was specifically chosen instead of to, since the preposition into seems to involve the crossing of a bound, and since the theme is entailed to cross the bound of the net or goal, it is entailed to traverse the entire path, making the sentence telic in an intuitive sense. However, it is difficult to get the traversal of the path under the scope of time adverbials. For example,

49. We launched the rocket out of the earth's atmosphere in six minutes

is quite odd as a description of the time it took for us to launch the rocket and for the rocket to leave the earth's atmosphere. This seems to be true for all verbs of this sort, even in different lexical fields. For example, the verb send is also punctual in this sense; 
as soon as I have put the package into the mail I have sent it. It does though include some kind of implied path, since the to-phrase with a verb like send seems selected and syntactically acts like a complement and not an adjunct. But (50a),

50. a. I sent the soldiers over the border in two days.

b. We launched the missile over the border in twenty seconds.

c. I rolled the ball into the ditch in three seconds.

also sounds odd as a description of the time it took for the package to make it over the border. We get the same effect in $(50 \mathrm{~b} \& \mathrm{c})$. [fn As Hana Filip has pointed out, if the referent of the direct object can be assigned a part structure, then the time adverbial can be understood as a description of the time the traversal of the path took places, as in I sent the soldiers over the border in two days, one soldier after another, so noone would notice them.] What seems to be going on here is that there is a difference between the status of the material that is actually lexicalized in the verb and that which is entailed by the rest of the sentence. This is actually unusual, since it is usually the case that nonlexicalized material participates fully in aspectual composition. (See also Filip, this volume). (51a) is atelic and (51b) is telic, although the result XP is not lexicalized.

51. a. I hammered the metal for five minutes.

b. I hammered the metal flat in five minutes

We have just seen two possible temporal relations between the subevents: temporal dependence, and temporal independence, with a punctual event being followed by a durative on. We can now move onto a complex event which is in some sense the mirror image of the first set of examples, where a durative activity is followed by a punctual change:

52. a. We voted her into the department.

b. New Yorkers voted Hillary Clinton into office.

Both examples involve a transition from one status to another, as a result of voting. The transition does not take place incrementally. When half the voting is over, the candidate is not halfway into the department or halfway into office, (not to mention that it is not the case that half of her is in the department or in office). Of course, vote here is a collective predicate and the durativity of the voting process probably derives from this. But this does not change the point that the event of voting is durative, while the resultant change is punctual. Here the relation between the two events also seems to be lexically specified. Another option is to say that this derives from our real-world knowledge of the process of voting, but it is unclear to me that this is any different from saying that it is lexicalized in the meaning of the verb.

Other examples of this sort were cited in Rappaport Hovav and Levin (2001):

53. a. The critics panned the show right out of town.

b. He partied his way out of a job 
In (a), the show was made to leave town only after the critics wrote their reviews, and in (b) it is likely that the loss of job happened suddenly after a series of partying events.

\subsection{Other Sources of Incremental Structure}

As already mentioned, Rothstein (2004) suggests that accomplishments derive their incremental structure from the BECOME event representing the change which the theme undergoes. In section 4.1 above, we saw that not all themes which provide an incremental structure undergo a change. In this section we look at cases in which the change lexicalized by the verb is not incremental, but the predication can nonetheless be one of an accomplishment.

Consider, for example the verb give, as in (52)

54. a. I gave the book to Mary.

b. *I gave the book halfway to Mary

c. *I gave the book towards Mary

d. I gave her the book in three minutes (after three minutes reading).

As Jackendoff (1996) points out, change of possession is conceived of as a two-point change, with the theme going from not being in the possession of the possessor, to the theme being in the possession of the possessor. They are then, aspectually, achievement verbs. But notice that if the object is chosen correctly, it can be taken to be an incremental theme, yielding an accomplishment:

55. I gave him the entire report in three hours (page, by page)

As pointed out in Dowty (1979) and further discussed in Beavers (in press) and Kearns (to appear), an in X time phrase is interpreted with an event delay reading with an achievement but with a true durative reading with an accomplishment. That is, I gave Mary the book in two minutes means that after an interval of two minutes, during which there was no event of giving, the book changed possession. In contrast, (53) has a reading in which the giving took place during the entire range of three hours, a reading associated with accomplishments.

\section{Conclusion}

The Vendler classes are determined on the basis of a number of familiar diagnostics, such as appearance and interpretation in the progressive, entailments from the progressive to the perfect, compatibility and interpretation with the variety of temporal adverbials. Most of these diagnostics, however, are not diagnostics of lexical properties, but rather of uses of lexical items in particular contexts. As is well-known, verbs that are basically classified as activities can be used in telic contexts.

56. a. John scrubbed the tiles for an hour. 
b. John scrubbed the tiles clean in an hour.

More dramatically, the class of gradual completion verbs such as dim and increase, show a range of aspectual properties: they can show the properties of activities, achievements and accomplishments (Kearns to appear).

57. a. Inflation increased for six years straight.

b. Inflation increased five percent in three months.

c. They predict that inflation will increase in three months.

So, these verbs cannot be classified once and for all either as activities, accomplishments or achievements. However, it is eminently clear that there is some basic lexical property which determines the ability of these verbs to appear in these contexts. I have suggested that this property is that of lexically encoding a scalar change.

As in any other system of classification, the features which determine the classes have theoretical significance, much more than the classes themselves. The semantic features which have been isolated in this paper help determine the aspectual potential of the verbs in question. There are three classes of verbs which can be assigned lexical properties which make them belong 'basically' to one of the Vendler classes. These are states, such as resemble, have and know, achievements, such as arrive, reach, and recognize, and activities, such as tickle and play, and read. The first class consists of verbs which encode no change, the second are verbs which encode a bipartite scale, and the third are verbs which encode a nonscalar change. Among the activities we distinguish between those which may relate to the direct object incrementally, such as read and eat, and those which may not, such as push and tickle. We have seen that verbs which encode a complex scalar change have the potential of serving as activities, achievements and accomplishments. Among the class of verb which lexicalize a nonscalar change are those which are associated with a second subevent, and there is a distinction between those which lexicalize temporal dependence between the subevents and those which do not. Are there any verbs which are basically classified as accomplishments? Filip and Rothstein (2006) suggest that in Germanic, there are no nonderived verbs which are lexical accomplishments. Potential candidates for verbs which are lexical accomplishments are verbs which lexicalize a complex bounded scale. We have seen, however, in section 3.2, that such verbs are not necessarily telic in English. This appears to support their contention. ${ }^{16}$

As discussed in section 4, there appears to be more justification for recognizing the fourway Vendler classification at the VP level, though here too, at least for the class of accomplishments, we have seen that there is ample reason for recognizing a variety of subtypes. It is perhaps not surprising that both at the lexical level and at the VP level,

\footnotetext{
${ }^{16}$ I suggest that there are indeed verbs in English which are lexical accomplishments: denominal verbs such as saddle and shelve, and castle (the move in chess, suggested to me by Edit Doron) and traversal object verbs such as traverse and cross. The former are denominal and the latter are Latinate in source. This suggests that the generalization that there are no Germanic accomplishment verb roots is still basically correct.
} 
there is the greatest amount of internal variation for predicates corresponding to accomplishments: in fundamental ways, accomplishments are the most 'complex' of the classes.

\section{$\underline{\text { References }}$}

Arad, M. 1989. VP-Structure and the Syntax-Lexicon Interface, doctoral dissertation, University College London.

Bach, E. 1981. On time, tense and aspect: and essay in English metaphysics. In Radical Pragmatics, P. Cole ed., 63-81. New York: Academic Press.

Beavers, John. In press. Scalar complexity and the structure of events". In Event Structures in Linguistic Form and Interpretation, Johannes Dölling and Tatjana Heyde-Zybatow (eds.). Berlin: Mouton de Gruyter.

Beavers, J. 2006. The aspectual behavior of ditransitives in English. Paper given at the Linguistic Society of America 80th Annual Meeting, Albuquerque, NM.

Boas, H. C. 2003. A Constructional Approach to Resultatives. Stanford: CSLI Publications.

Borer, H. 2005. Structuring Sense. Oxford: Oxford University Press.

Carlson, L. 1981. Aspect and quantification. In Tense and Aspect, Syntax and Semantics 14. P. Tedeschi and A. Zaenen eds. New York: Academic Press.

Dixon, R. M. W. 1982. Where have all the adjectives gone? In: Robert M.W. Dixon, Where Have All the Adjectives Gone? and Other Essays in Semantics and Syntax. 1-62 Berlin-Amsterdam-NewYork: Mouton. .

Dowty, D. 1979. Word Meaning and Montague Grammar. Dordrecht: Reidel.

Dowty, D. 1991. Thematic proto-roles and argument selection, Language 67, 547-619. Erteschik-Shir, N. and T. Rapoport 2004. Path predicates. In The Syntax of Aspect. N. Erteschik-Shir and T. Rapoport eds., 65-86. Oxford: Oxford University Press.

Filip, H. 2004a. "Prefixes and the Delimitation of Events." A special issue of Journal of Slavic Linguistics, ed. by Wayles Browne and Barbara Partee. Volume 11, 1. Pp.55-101.

Filip, H. 2004b. "The telicity parameter revisited." SALT 14.

Filip, H. and S. Rothstein. 2006. Telicity as a semantic parameter. FASL 14. Pp. 139156.

Hout, van A. 2000. "Projection based on event structure," in Lexical Specification and Insertion. P. Coopmans, M. Everaert, and J. Grimshaw, eds., 403-427. Amsterdam: John Benjamins.

Kearns, K. to appear. Telic senses of deadjectival verbs. Lingua.

Kratzer, A. 2000 Building statives. In BLS 26.

Kennedy, C. and L. McNally 2005. Scale structure, degree modification and the semantics of gradable predicates. Language 81.2:345-381.

Koontz-Garboden, A. and B. Levin (in press) 'The Morphological Typology of Change of State Event Encoding", Proceedings of the 4th Mediterranean Morphology Meeting, Catania, Italy.

Kratzer, A. 2004. "Telicity and the Meaning of Objective Case." Guéron, J. and J. Lecarme (eds.). The Syntax of Time. Cambridge/Mass.: The MIT Press, 389-424. 
Krifka, M. 1992. Thematic relations as links between nominal reference and temporal constitution. In Ivan Sag \& Anna Szabolcsi (eds.), Lexical Matters, 29-53. CSLI Publications, Chicago University Press,

Krfika, M. 1998. The origins of telicity. In Events and Grammar, S. Rothstein, ed., 197235. Dordrecht: Klwuer.

Krifka, M. 1999. Manner in dative alternation. Proceedings of WCCFL 18, Cascadilla Press.

Jackendoff, R. 1987. The status of thematic relations in linguistic theory. Linguistic Inquiry 18:369-411.

Jackendoff, R. 1990. Semantic Structures. Cambridge, Mass: MIT Press.

Jackendoff, R. 1996. The proper treatment of measuring out, telicity, and perhaps even quantification in English. Natural Language and Linguistic Theory, 14, 305-354.

Levin, B. and M. Rappaport Hovav (1995) Unaccusativity: at the Sytnax-Lexical Semantics Interface. Cambridge, Mass: MIT Press.

Levin, B. and M. Rappaport Hovav (1999). Two structures for compositionally derived events. In Proceedings of SALT 9. T. Matthews and D. Strolocitch eds., CLC Publications, Cornell University.

Levin, B. and M. Rappaport Hovav (2006)

Mittwoch, A. 1991. In defense of Vendler's achievements, in Belgian Journal of Linguistics 6, 71-85.

Mourelatos, A.P.D. 1978. Events, processes and states. In Syntax and Semantics 14., Tense and Aspect, New York: Acadmic Press.

Parsons, T. 1990. Events in the Semantics of English. Cambridge, Mass: MIT Press.

Pinker, S. 1989. Learnability and Cognition: The Aquicistion of Argument Structure. Cambridge, Mass: MIT Press.

Rappaport Hovav, M. and B. Levin 1998. Building verb meanings, in The Projection of Arguments, M. Butt and W. Geuder, eds. 97-134. Stanford: CSLI.

Rappaport Hovav, M. and B. Levin 2001. An event structure account of English resultatives. Language 77:766-797.

Rappaport Hovav, M. and B. Levin 2004. Change of state verbs: implications for theories of argument projection. In The Syntax of Aspect. N. Erteschik-Shir and T. Rapoport eds., 274-286. Oxford: Oxford University Press.

Ritter, E. and S. Rosen 1998. "Delimiting events in syntax," in The Projection of Arguments, M. Butt and W. Geuder, eds. 135-64. Stanford: CSLI.

Rothstein, S. 2005 Structuring Events, Oxford: Blackwell.

Rothstein, Susan, in press Two puzzles for a theory of Lexical Aspect: the case of semelfactives and degree adverbials. To appear in J. Dölling and T Zybatow (eds) Event Structures. De Gruyter.

Rotstein. C. and Y. Winter 2004. Total adjectives vs. partial adjectives: scale structure and higher order modifiers. Natural Language Semantics 12:259-288.

Simpson, J. 1983. Resultatives, in Papers in Lexical-Functional Grammar. L. Levin, M. Rappaport and A. Zaenen, eds., 143-157. Bloomington, Indiana: Indiana University Linguistics Club.

Svenonius, P. Icelandic Case and the Structure of Events Journal of Comparative Germanic Linguistics 5:197-225 
Talmy, L. 1985. Lexicalization patterns: semantic structure in lexical forms. In Language Typology and Syntactic Description 3: Grammatical Categories and the Lexicon. T. Shopen, ed., 67-149. Cambridge: Cambridge University Press

Tenny, C. 1994. Aspectual Roles and the Syntax-Semantics Interface. Dordrecht: Kluwer.

Van Valin, R.D., Jr. and R.J. LaPolla 1997. Syntax: Structure, Meaning and Function. Cambridge: Cambridge University Press.

Vendler, Z. 1957. Verbs and Times, Philosophical Review 56, 143-160. Reprinted in Linguistics in Philosophy, Z. Vendler, ed., 97-121. Ithaca: Cornell Univeristy Press.

Verkuyl, H.J. 1989. Aspectual classes and aspectual composition, Linguistics and Philosophy 12, 39-94.

Wechsler, S. 2004. Resultatives under the 'event-argument homomorphism'model of telicity. In The Syntax of Aspect. N. Erteschik-Shir and T. Rapoport eds., 255273. Oxford: Oxford University Press. 